\title{
Hedef Programlama ve Analitik Hiyerarşi Prosesi (AHP) ile Yeniden Üretim Sistemlerinin Stok Kontrolünün İncelenmesi*
}

\author{
Investigation of Inventory Control of Remanufacturing Systems with Goal \\ Programming and Analytic Hierarchy Process (AHP)
}

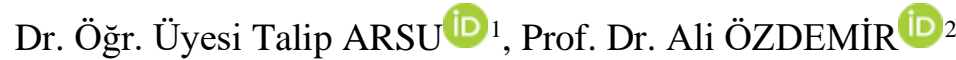

\begin{abstract}
$\ddot{O} z$
Faydayı ön planda tutan işletmeler, geçmiş deneyimlerinden yararlanarak kendilerine uzun vadede başarıyı getirecek olan bazı gerçekçi hedefler koymak zorundadır. Bu hedefleri koyarken karşılaşılacak birçok belirsizlik ve işletmelerin göz önünde bulundurması gereken birçok kısıt vardır. İşte bu belirsizlik ortamında işletmenin koyduğu gerçekçi hedefleri doyuma ulaştırması ve bu bilgiler ışığında geleceğini şekillendirmesi gerekmektedir. Bu da Çok Amaçlı Karar Verme (ÇAKV) metotlarından Hedef Programlama ile mümkündür. Bu çalışmada otomotiv yedek parça sektöründe faaliyet gösteren bir işletmenin yeniden üretim sistemi ürün portföyünden, üç ürün için üç dönemlik stok kontrol politikası hedef programlama ile modellenmiş ve çözülmüsştür. Hedef Programlama modelinin amaç fonksiyonu katsayıları hesaplanırken Çok Nitelikli Karar Verme (ÇNKV) metotlarından Analitik Hiyerarşi Prosesi (AHP) kullanılmıștır. Önerilen modeldeki beș ana hedeften üç tanesi (toplam stoklama maliyetini minimize etme hedefi, net karı maksimize etme hedefi ve fazla mesai ile gerçekleştirilen üretim maliyetini minimize etme hedefi) herhangi bir pozitif veya negatif sapma meydana gelmeden başarılmıştır. İki hedefte (dönemlik stoklama kapasitesini aşmama hedefi ve dönemlik ürün talebini karşılama hedefi) ise pozitif veya negatif sapmalar meydana gelmiştir. Fakat genel olarak birçok hedefini başarıyla doyuma ulaştıran işletme kısmen başarılı bir seyir izlemektedir. Ayrıca bu çalışmada önerilen hedef programlama modeli işletmenin stok kontrol politikası hedeflerini başarılı br şekilde doyuma ulaştırmıştır. Çözüm sonucunda ulaşılan değerler ile işletmenin kendisine koyduğu hedefler karşılaştırılarak yorumlanmıştır.
\end{abstract}

Anahtar Kelimeler: Stok yönetimi, tersine lojistik, yeniden üretim, hedef programlama, Analitik Hiyerarşi Prosesi (AHP)

Makale Türü: Araştırma

\begin{abstract}
Companies that prioritize the benefit have to set some realistic goals that will bring them success in the long run, taking advantage of their past experience. There are many uncertainties to face when setting these goals and many constraints that the companies must take into account. In this uncertainty environment, it is necessary to satisfy the realistic goals set by the companies and to shape its future in the light of this information. This is also possible with Goal Programming, one of the Multi-Objective Decision Making (MODM) methods. In this study, a three-period inventory control policy for three products in a company, which operating in the automotive spare parts sector, from the product portfolio is modeled and solved with goal programming. Analytical Hierarchy Process (AHP), one of the Multi-Attribute Decision Making (MADM) methods, was used to calculate the objective function coefficients of the Goal Programming model. Three of the five main goals (the goal of minimizing total stocking cost, the goal of maximizing net profit and the goal of minimizing overtime production costs) in the proposed model were achieved without

\footnotetext{
*Bu çalışmanın ilk hali 13.07.2013 tarihinde Dokuz Eylül Üniversitesi, Sosyal Bilimler Enstitüsü, Yönetim Bilimi programında yüksek lisans tezi olarak savunulmuştur. Ayrıca bu çalışmanın özeti, 17-20 Ekim 2018 tarihleri arasında Antalya'da düzenlenen 19. Ekonometri Yöneylem Araştırması ve İstatistik Kongresi’nde sunulmuştur.

${ }^{1}$ Aksaray Üniversitesi, Sosyal Bilimler Meslek Yüksek Okulu, taliparsu@aksaray.edu.tr.
}

${ }^{2}$ Dokuz Eylül Üniversitesi, İktisadi ve İdari Bilimler Fakültesi, ali.ozdemir@ deu.edu.tr.
\end{abstract}

Atıf için (to cite): Arsu, T ve Özdemir, A. (2019). Hedef Programlama ve Analitik Hiyerarşi Prosesi (AHP) ile Yeniden Üretim Sistemlerinin Stok Kontrolünün İncelenmesi. Afyon Kocatepe Üniversitesi Sosyal Bilimler Dergisi, 21(4), $1230-1245$. 
any positive or negative deviation. The other two main goals (the goal of not exceeding the periodical storage capacity and the goal of meet the demand for periodical products) have positive or negative deviations. However, in general, the company, which successfully satisfies many of its objectives, is partially successful. In addition, the goal programming model proposed in this study successfully satisfy the inventory control policy objectives of the enterprise. The values obtained as a result of the solution are compared with the goals set by the company.

Keywords: Stock management, reverse logistics, remanufacturing, goal programming, Analytic Hierarchy Process (AHP)

Paper Type: Research

\section{Giriş}

Günümüz piyasa ortamlarında küreselleşmenin etkisi ile işletmeler esneklikten uzaklaşmış ve alınacak en küçük kararların bile birçok değişken göz önünde bulundurularak alınması hayati bir önem kazanmıştır. Bu belirsizlik ortamı, zamanla işletmeleri isabetli tahminin ne kadar gerekli olduğuna inandırmıştır. Tahmin yapması gereken işletme, geçmiş tecrübelerinden yararlanarak kendine bir takım kısıtlar/hedefler oluşturur ve bu kısıtlar/hedefler ile geleceği şekillendirmeye çalışırlar. İşte bu birçok değişken, kısıt ve hedefin birlikte ele alındığ ve bu hedeflerin hepsinin doyuma ulaştırılması gerekliliği, Hedef Programlamayı işletmelerin problem çözmede kullandığı başlıca yöntemler arasına sokmuştur.

Bu çerçevede gerçekleştirilen uygulamanın amacı, ülkemizde çok fazla yaygın olmayan yeniden üretim (re-manufacturing) uygulamalarının sağladığ israfını önleme faaliyetlerinin verimliliğini arttırmak ve stoklarının yönetilmesi kararlarının Çok Nitelikli Karar Verme (ÇNKV) metotlarından Analitik Hiyerarşi Prosesi (AHP) ve Çok Amaçlı Karar Verme (ÇAKV) metotlarından Hedef Programlama ile yapılmasını sağlamaktır.

Bu bağlamda bu çalışmada önce kısaca stok yönetimi, tersine lojistik ve yeniden üretim konularına değinilmiş sonrasında ise bir yeniden üretim işletmesinin gerçek verileri kullanılarak hedef programlama modeli geliştirilmiş ve çözülmüştür.

\section{Kavramsal Çerçeve}

\subsection{Stok Yönetimi}

İşletmeler gelecekte talepte meydana gelebilecek olası dalgalanmalar sonucunda oluşacak arz yetersizliğini engellemek ve yığın üretimin avantajlarından faydalanmak adına stok yaparlar. Bu stokların yönetimi işletmeler için büyük bir önem arz etmektedir.

Stok kavramı hakkında yapılan birçok tanımdan bir kaçı şunlardır; Bir organizasyonun kullandığı madde veya kaynak birikimine stok adı verilmektedir (Chase v.d., 1998: 582). Bir başka tanıma göre stok, ilerleyen dönemlerde üretim gerçekleştirilirken kullanılabilecek veya pazarlanabilecek materyal, yarı-işlenmiş ve tamamlanmış ürünlerin toplamıdır (Demir ve Gümüşoğlu, 2009:485).

Üretim açısından stok, genellikle işletmenin ürün çıktısının bir parçası haline gelen veya çıktıya katkı sağlayan öğeler anlamına gelmektedir. Perakende sektöründeki stok ise satılmak üzere hazır bulundurulan mamullerden ve işlemleri yönetmek için gerekli malzemelerden oluşur (Chase v.d., 1998: 582).

\subsection{Tersine Lojistik ve Yeniden Üretim}

Geleneksel bir üretim ortamında, tek bir kaynaktan üretilen yeni ürünlerin birden çok hedefe teslim edilmesi işlemine bilindiği gibi "İleriye Doğru Lojistik" (ileriye doğru dağıtım) denmektedir. Diğer yandan, birden fazla kaynaktan elde edilen ve tek bir ürün kazanım tesisine getirilen kullanılmış ürünlerin üretim ortamına tersten akışına da "Tersine Lojistik" veya "Tersine Dağıtım" denmektedir (Gungor ve Gupta, 1999: 827). Bir diğer tanıma göre ise, Tersine Lojistik, 
olası bir geri dönüşüm, yeniden üretim veya imha için tüketim noktasından, bir üretim birimine sistematik olarak ürün veya parçaların gönderilmesi sürecidir (Dowlatshahi, 2005: 3455).

Tersine lojistik geri kazanım seçenekleri yapılış biçimlerine göre farklılık göstermektedir. Uygulamada karşılaşılan geri kazanım seçenekleri şu şekildedir;

Tamir (Repair): Tamirin amacı, kullanılan ürünleri “çalışır vaziyette” ürünler haline getirmektir. Tamire uğramış ürünlerin kalitesi genellikle yeni ürünlerin kalitesinden çok daha azdır (Kumar ve Malegeant, 2006: 1129). Ürünlerin tamiri tespit ve/veya kırık (bozuk) parçaların değiştirilmesi evrelerini içerir. Diğer parçalar temel olarak etkilenmez. Tamir çoğunlukla sadece bazı parçaların sökülmesi ve takılmasını gerektirir. Tamir işlemleri, müşterinin olduğu yerde veya üretici kontrollü onarım merkezlerinde yapılabilir (Thierry vd., 1995:118).

Yenileştirme (Refurbishing): Yenileştirmenin amac1, kullanılan ürünleri belirlenen kalite seviyelerine getirmektir. Kalite standartları yeni ürünlere nazaran daha az sıkıdır. Kullanılan ürünlerin parçalar halinde demontajından sonra, bütün kritik parçalar kontrol edilir ve sabitlenir veya değiştirilir. Onaylanan parçalar, yenileştirilmiş ürün ile yeniden birleştirilir. Bazen ürün yenileştirme sürecinde eski parçalar, teknik olarak daha iyi olan parçalarla değiştirilerek, ürünün iyileştirmesi gerçekleştirilir. Bu işleme askeri ve ticari uçakların yenileştirilmesi örnek teşkil edebilir. Yenileştirme uçakların kalitelerini ve servis ömürlerini önemli ölçüde geliştirir. Ancak, kalan servis ömrü genellikle yeni uçak ortalama hizmet ömrüne göre daha azdır (Thierry vd., 1995: 119).

Parça Alma (Cannibalization): Tablo 1'deki sıralamaya göre ilk üç geri kazanım seçeneğinde kullanılmak üzere, nispeten az sayıdaki yeniden kullanılabilir parçaların veya modüllerin kurtarılmasıdır (Kumar ve Malegeant, 2006: 1129). Bu parçalar, tamir, yenileştirme veya diğer ürünlerin ve parçaların yeniden üretimi ile tekrar kullanılacak hale getirilir. Parça alınan kısımlar için kalite standardı, yeniden kullanılacağı sürece bağlıdır (Thierry vd., 1995:119).

Geri Dönüşüm (Recycling): Orijinal amacıyla kullanım ve enerji geri kazanımı hariç, organik dönüşüm dâhil olmak üzere atıkların bir üretim sürecine tabii tutularak yeni ürün üretiminde kullanılmasıdır. Geri dönüşüm, katı atık içerisindeki geri dönüştürülebilir maddelerin ekonomiye geri kazandırılması işlemidir (Kaçtıŏlu ve Şengül, 2010: 93).

Yeniden Üretim (Remanufacturing): Yeniden üretimin amac1 kullanılan ürünleri yüksek kalite standardına sahip yeni ürünler haline getirmektir. Kullanılan ürünler tamamen demonte edilmekte ve bütün modülleri kapsamlı olarak kontrol edilmektedir. Yıpranmış ve eskimiş parça ve modüller yenileri ile değiştirilip, tamir edilebilir parça ve modüller, sabit ve yoğun olarak test edilmektedir. Onaylanan parçalar modüller halinde alt montajdan geçer ve daha sonra yeniden üretilmiş ürünlerin içerisine monte edilir. Yeniden üretim, teknoloji yükseltme ile birlikte kullanılabilir. Örneğin, kullanılmış makine parçaları genellikle "daha yeni" kalite ve teknolojiyle, yeni makine maliyetinin \%50-60'1 arasında bir maliyetle yenilenebilir. BMW yıllardır motor, marş motoru ve alternatörler gibi yüksek maliyetli parçaları yeniden üretim sürecine sokmaktadır. Yeniden üretilmiş parçalar BMW alım-satım bölümü tarafından yüksek kalite standartlarına göre test edilmektedir. Yenilenen parçalar aynı kalite ve garanti koşullarında ve yeni parçalardan \%30-50 arası daha uygun fiyata yeniden satılmaktadır (Thierry vd., 1995: 119).

Yeniden üretim, parçaların demonte edilerek temizlendiği, kontrollerinin yapıldığı, sinıflandırıldığı ve üretim süreci sonucunda yeniden kullanılabilir hale getirildiği bir işlemler bütünü olarak tanımlanmaktadır (Gürler, 2010:32). Ürün geri kazanım seçeneklerinin karşılaştırması Tablo 1'de gösterilmektedir. 
Tablo 1. Ürün geri kazanım seçeneklerinin karșılaștırılması

\begin{tabular}{llll}
\hline & $\begin{array}{l}\text { Demontaj } \\
\text { Seviyesi }\end{array}$ & Kalite Gereksinimleri & Sonuçta ortaya çıkan ürün \\
\hline Tamir & Ürün Düzeyi & $\begin{array}{l}\text { Ürünü çalışır vaziyete geri } \\
\text { getirme }\end{array}$ & $\begin{array}{l}\text { Bazı kısımlar sabitlenir veya } \\
\text { yedek parça ile değiştirilir. }\end{array}$ \\
\hline Yenileştirme & Modül Düzeyi & $\begin{array}{l}\text { Tüm kritik modülleri } \\
\text { incelemek ve belirlenen } \\
\text { kalite düzeyine getirmek }\end{array}$ & $\begin{array}{l}\text { Bazı modüller tamir edilir/ } \\
\text { değiştirilir; Potansiyel } \\
\text { yükseltmeler uygulanır }\end{array}$ \\
\hline Yeniden Üretim & Parça Düzeyi & $\begin{array}{l}\text { Tüm modülleri ve parçaları } \\
\text { kontrol etmek ve yeni kalite } \\
\text { düzeyine yükseltmek }\end{array}$ & $\begin{array}{l}\text { Kullanılmış ve yeni } \\
\text { modüller/ parçalar } \\
\text { birleştirilir; Olası } \\
\text { yükseltmeler yapılır }\end{array}$ \\
\hline \multirow{2}{*}{ Parça Alma } & Seçici Parça Alımı & $\begin{array}{l}\text { Yeniden kullanılan } \\
\text { parçaların sürecine göre } \\
\text { değişir }\end{array}$ & $\begin{array}{l}\text { Bazı parçalar tekrar } \\
\text { kullanılır; kalanlar geri } \\
\text { dönüşüm/imha yapıllır }\end{array}$ \\
\hline \multirow{2}{*}{ Geri Dönüşüm } & Malzeme Düzeyi & $\begin{array}{l}\text { Orijinal parçaların üretimi } \\
\text { için yüksek, diğerleri için } \\
\text { daha az }\end{array}$ & $\begin{array}{l}\text { Malzemeler yeni ürünün } \\
\text { üretiminde yeniden kullanılır }\end{array}$ \\
\hline
\end{tabular}

Kaynak: Thierry vd., 1995: 120

Literatürde yeniden üretim sürecinin stok yönetimi ve stok kontrol politikalarını inceleyen birçok çalışma bulunmaktadır; Van der Laan v.d. (1996), yeniden üretim sistemlerinde kullanılmak üzere bir stok modeli geliştirmiştir. Van der Laan ve Solomon (1997) üretim, yeniden üretim ve bertaraf işlemlerine dair stokastik bir stok sistemi geliştirmiştir. Van der Laan v.d. (1999) üretim ve yeniden üretim işlemlerinin aynı anda meydana geldiği sistemlerin üretim planlaması ve stok kontrolü üzerine bir çalışma yapmıştır. Kongar ve Gupta (2000) karar vericilerin kendilerine özgü tercihlerine yönelik bir yeniden üretim tedarik zinciri ortamında, planlanan ve planlanmayan stokların kabul edilebilir tolerans sınırlarını belirlemek için kantitatif bir metodoloji sunmuştur. Inderfurth ve Van der Laan (2001) uygun bir stok konumu belirleyerek basit politikaların performansını önemli ölçüde geliştirebildiğini göstermiştir. Mahadevan v.d. (2003) yeniden üretim kapsamında, üretim kontrolü, stok yönetimi ve ürün kurtarma operasyonuna odaklanmıştır. Zhou v.d. (2006) hem üretim hem de yeniden üretim sistemlerini içine alan bir hibrit sistem ele almıştır. Takahashi v.d. (2007) üretim ve bertaraf ile ilgili bir yeniden üretim sistemini göz önünde bulundurarak parça ve ürünlerin üretimi için kullanılan malzeme ve materyallerin, bertaraf atıklarını sınıflandıran bir ayrıştırma sürecini ele almıştır. Nenes v.d. (2010) hem yeni ürün talepleri hem de kullanılan ürünlerin geri dönüşlerinin stokastik olduğu bir sistem için alternatif politikalar geliştirmiştir. Chung ve Wee (2011) küresel ssınma, çevre bilinci ve ürün yaşam döngüsünün kısalmasından kaynaklanan ekolojik koruma çabaları ve kaynak kullanımı için daha fazla harcama yapıldığının bilincinde olduklarından, çalışmalarında kısa yaşam döngüleri ile entegre bir üretim envanter modeli geliştirmiştir.

Literatürde yeniden üretim sistemlerinin stok kontrolünü inceleyen birçok çalışma mevcut olmasına rağmen hedef programlama ile modellenen bir çalışmaya rastlanamamıştır. Ayrıca hedef programlama modeli ağırlıklarının AHP ile belirlenmesi kantitatif modelin objektifliğini daha da arttırdığından literatüre katkı sağlamıştır.

\section{Yöntem}

\subsection{Araştırmanın Amacı}

Araştırmanın amacı, ülkemizde çok fazla yaygın olmayan yeniden üretim (remanufacturing) uygulamalarının sağladığı çevre kirliliğini azaltma ve kaynak israfını önleme faaliyetlerinin verimliliğini arttırmak ve stoklarının yönetilmesi kararlarının kantitatif karar verme tekniklerinden AHP ve Hedef Programlama ile yapılmasını sağlamaktır. 


\subsection{Araștırmanın Yöntemi}

Yapılan çalışmada Özdemir (2005)'in KOBİ'lerin stok kontrolü için geliştirdiği hedef programlama modeli kullanılmıştır. Kullanılan Hedef Programlama modelinin amaç fonksiyonu ağırlıkları ise AHP ile belirlenmiştir.

Araştırmanın yapıldığı otomotiv yedek parça üretim işletmesinin ürün yelpazesinin büyük bir kısmını direksiyon kutuları oluşturmaktadır. Uygulamada da yeniden üretime tabi tutulan ve talep miktarları en yüksek olan üç direksiyon kutusunun, üç dönemlik üretim, talep, satış ve stok miktarları dikkate alınmış ve hedefler çerçevesinde model kurularak LINGO 11.0 ile çözülmüştür. Ulaşılan değişken değerleri ve hedeften sapmalar, işletmenin hedefleri ile karşılaştırılarak işletmenin verimliliğine arttırabilecek önerilerde bulunulmuştur.

\subsubsection{Hedef Programlama}

Hedef Programlama, çoklu alt hedefleri olan tek hedefli karar problemlerinin yanı sıra, çoklu alt hedefleri olan çok hedefli problemlerin çözüm bulduğu doğrusal programlamanın özel bir uzantısıdır (Wise ve Perushek, 2000:166-167).

Hedef programlama çok hedefli karar verme sorunları ile başa çıkmak için geliştirilen birçok modelden biridir. Bu model karar vericinin uygun bir dizi çözüm arasından en iyi çözümü ararken, aynı zamanda birçok hedefi hesaba katmasını sağlar (Aouni ve Kettani, 2001:226). Charnes ve Cooper (1961) tarafindan ortaya atılan Hedef Programlama Lee (1972), Charnes ve Cooper (1977) ve Ignizio (1978, 1983 ve 1989) tarafindan geliştirilmiştir. Yöntemde karar vericilerin ulaşmak istediği her amaç için hedefler belirlenmektedir. Tercih edilen bir çözümden sonra hedeflerden sapmaları minimize edecek sonuç tanımlanır. Hedef Programlamanın matematiksel modeli aşağıdaki gibi ifade edilir (Charnes ve Cooper, 1977: 41).

$\operatorname{Min} Z=\sum_{i \in m}\left(d_{i}^{+}+d_{i}^{-}\right)$

Kisitlar;

$\sum_{j=1}^{n} a_{i j} x_{j}-d_{i}^{+}+d_{i}^{-}=b_{i}$

$x_{j}, d_{i}^{+}, d_{i}^{-} \geq 0 \quad i=1,2, \ldots, m \quad j=1,2, \ldots, n$

Burada;

$d_{i}^{+}:$Amaçtan pozitif sapmalar

$d_{i}^{-}$: Amaçtan negatif sapmalar

$a_{i j}:$ Kisit fonksiyonu katsayıları

$b_{i}$ : Sağ taraf sabitleri

Uygulanan hedef programlama türüne göre amaç fonksiyonu ve kısitlar farklılık gösterebilse de genel hedef programlama fonksiyonu yukarda gösterildiği gibidir.

\subsubsection{Analitik Hiyerarşi Prosesi (AHP)}

AHP, karmaşık Çok Kriterli Karar Verme (ÇKKV) problemlerini çözmek için tasarlanmıştır. AHP, her kriterin göreli önemi hakkında yargılar sağlar ve sonrasında da her bir kriter kullanılarak bütün karar alternatiflerinden bir tercih belirlemek için karar vericiye yardımcı olur. AHP'nin çıktısı karar verici tarafından ifade edilen tercihlere göre karar alternatifleri içerisinde bir öncelik sıralamasıdır (Anderson v.d., 2001:733).

Uzmanlardan veya karar vericilerden toplanan veriler, hiyerarşik yapıya karşıllk gelen, kalitatif ölçekli alternatiflerin ikili karşılaştırmasından oluşur (Bhushan ve Rai, 2004:16). Thomas L. Saaty tarafından geliştirilen söz konusu ölçek Tablo 2'de gösterilmiştir. 
Tablo 2. AHP önem düzeyleri

\begin{tabular}{lll}
\hline $\begin{array}{l}\text { Önem } \\
\text { Yoğunluğu }\end{array}$ & Tanım & Açıklama \\
\hline $\mathbf{1}$ & Eşit Önem & İki faaliyet amaca eşit düzeyde katkı sağlar \\
\hline $\mathbf{3}$ & $\begin{array}{l}\text { Birinin diğerine göre } \\
\text { cok az önemli olması }\end{array}$ & Deneyim ve yargı bir faaliyeti diğerine çok az tercih ettirir \\
\hline $\mathbf{5}$ & $\begin{array}{l}\text { Kuvvetli derecede } \\
\text { önemli }\end{array}$ & $\begin{array}{l}\text { Deneyim ve yargı bir faaliyeti diğerine çok kuvvetli bir } \\
\text { derecede tercih ettirir }\end{array}$ \\
\hline $\mathbf{7}$ & $\begin{array}{l}\text { Cok kuvvetli düzeyde } \\
\text { önemli }\end{array}$ & $\begin{array}{l}\text { Bir faaliyet güçlü bir şekilde tercih edilir ve baskınlı̆̆ } \\
\text { uygulamada rahatlıkla görülür }\end{array}$ \\
\hline $\mathbf{9}$ & Aşırı derecede önemli & $\begin{array}{l}\text { Bir faaliyetin diğerine tercih edilmesine ilişkin deliller çok } \\
\text { büyük güvenilirliğe sahiptir }\end{array}$ \\
\hline $\mathbf{2 , 4 , 6 , 8}$ & Orta değerler & $\begin{array}{l}\text { Uzlaşma gerektiğinde kullanılmak üzere yukarıda listelenen } \\
\text { yargıllar arasinda yer alan değerler }\end{array}$ \\
\hline
\end{tabular}

Kaynak: Saaty ve Sodenkamp, 2010: 95

Öncelikle problem için uzmanlardan alınan girdi verileri ile yüksek önem düzeyine sahip amaçların başarılmasına (veya tatmin edilmesine) katkıda bulunmayı sağlayacak bir düzeydeki karar elemanlarının karşılaştırmaları ikili karşılaştırma matrislerini oluşturur (Zahedi, 1986:98). Daha sonra, aynı seviyeye ait kriterlerin ve alt kriterlerin her birine göre göreli önemleri hesaplanır. Niteliklerin her çifti için, uzmanlardan diğerine göre "ne kadar önemli" sorusunun cevab1 istenir (Giove v.d., 2009:66). Verilen cevaplarla oluşturulan matrisler 1şı̆̆ında çözüm yapılarak amaçların ağırlıkları belirlenir.

\subsection{Hedef Programlama Modelinde Kullanılan İşletme Bilgileri}

\subsubsection{Hedef Programlama Modeli Notasyonu (Karar Değişkenleri ve Parametreler)}

Modelde kullanılan karar değişkenleri ve parametreler her bir dönem için ayrı ayrı harflendirilmiştir. Üç ürün ve üç dönem kullanılacağından ürünler “ $\mathrm{j}=\mathrm{a}, \mathrm{b}, \mathrm{c}$ ”, dörder aylık üç dönem de "i=1, 2, 3" olarak gösterilmiştir.

\section{Karar Değişkenleri}

$n_{i}^{j}=\mathrm{i}$. periyotta normal mesai ile j ürününden üretilen miktarı

$f_{i}^{j}=$ i. periyotta fazla mesai ile j ürününden üretilen miktarı,

$i_{i}^{j}=$ i. periyotta $\mathrm{j}$ ürünü dönem sonu stoku,

$i_{i-1}^{j}=$ i. periyotta $\mathrm{j}$ ürünü dönem başı stoku,

$d_{x}^{-}=\mathrm{y}$. hedeften negatif sapma,

$d_{x}^{+}=y$. hedeften pozitif sapma,

\section{Parametreler}

$w_{x}^{-}=\mathrm{x}$. hedeften negatif sapmanın ağırlığı,

$w_{x}^{-}=\mathrm{x}$. hedeften pozitif sapmanın ağırlığ,

$C_{i}^{j}=$ i. periyotta j ürünü talep miktarı,

$I^{j}=$ a ürünü dönem sonu stok miktarı hedefi,

$K=$ Dönemlik kâr hedefi,

$M^{j}=$ Dönemlik fazla mesai ile üretim maliyeti hedefi (j ürünü), 
$N^{j}=$ İşletmenin her dönem normal mesai ile üretebileceği maks. üretim mik.(j ürünü)

$F^{j}=$ İşletmenin her dönem fazla mesai ile üretebileceği maks. üretim mik.(j ürünü),

$r=$ Fiyatın yüzdesi olarak ifade edilen stoklama maliyeti,

$P_{i}^{j}=\mathrm{j}$ ürünü i. periyottaki birim satış fiyatı,

$v_{i}^{j}=$ i. periyotta normal mesai ile j ürünü birim üretim maliyeti,

$y_{i}^{j}=$ i. periyotta fazla mesai ile j ürünü birim üretim maliyeti,

$h_{i}=$ i. periyottaki birim stoklama maliyeti (bütün ürünler için),

$k=$ Toplam dönem sayısı.

\subsubsection{Hedef Programlama Modelinin Kurulacağı İsletme Verileri}

- İşletmenin dört aylık her dönem için yeniden üretilmiş ürünlere ayırdığı stoklama kapasitesi her bir ürün grubu için 50 birimdir.

- 01.01.2011 tarihli dönem başı başlangıç stokları A ürünü için 124 birim, B ürünü için 109 birim, C ürünü için 64 birimdir.

- Ürünün birim stoklama maliyeti her bir ürün grubu için eşit ve 5 TL'dir.

- Birim satış fiyatları A ürünü için 193 TL, B ürünü için 140 TL, C ürünü için ise 191 TL'dir.

- Ürünlere ilişkin talep miktarlar Tablo 3'te verilmiştir

Tablo 3. Ürünlere ilişkin talep miktarları

\begin{tabular}{llll}
\hline & A Ürünü & B Ürünü & C Ürünü \\
\hline 1. Dönem & 60 Adet & 32 Adet & 34 Adet \\
\hline 2. Dönem & 34 Adet & 100 Adet & 80 Adet \\
\hline 3. Dönem & 8 Adet & 88 Adet & 10 Adet \\
\hline
\end{tabular}

- Normal mesai ile üretim kapasitesinin aşan miktarları karşılayabilmek için işletme fazla mesai ile üretim yapabilmektedir.

- İşletme her dönem normal mesai saatlerinde her bir ürün grubundan minimum 35 adet üretmelidir.

- İşletme her dönem fazla mesai saatlerinde her bir ürün grubundan maksimum 30 adet üretilmelidir.

- Normal veya fazla mesaide üretim yapılması halinde birim üretim maliyetleri Tablo 4'te verilmiştir. 
Tablo 4. Normal ve fazla mesai ile üretim maliyetleri

\begin{tabular}{lllllll}
\hline \multirow{2}{*}{\begin{tabular}{l} 
Kaliyet \\
\cline { 2 - 6 } İlk Madde
\end{tabular}} & $91 \mathrm{TL}$ & $84 \mathrm{TL}$ & $89 \mathrm{TL}$ & $91 \mathrm{TL}$ & $84 \mathrm{TL}$ & $89 \mathrm{TL}$ \\
\hline A Ürünü & B Ürünü & C Ürünü & A Ürünü & B Ürünü & C Ürünü \\
\hline İşçilik & $20 \mathrm{TL}$ & $20 \mathrm{TL}$ & $20 \mathrm{TL}$ & $26 \mathrm{TL}$ & $26 \mathrm{TL}$ & $26 \mathrm{TL}$ \\
\hline Diğer & $3.15 \mathrm{TL}$ & $2,32 \mathrm{TL}$ & $3.55 \mathrm{TL}$ & $7.15 \mathrm{TL}$ & $6,32 \mathrm{TL}$ & $7,55 \mathrm{TL}$ \\
\hline Toplam & $125 \mathrm{TL}$ & $110 \mathrm{TL}$ & $120 \mathrm{TL}$ & $135 \mathrm{TL}$ & $120 \mathrm{TL}$ & $130 \mathrm{TL}$ \\
\hline
\end{tabular}

\subsubsection{Hedef Programlama Modeli Varsayımlart}

- Ürünlerin birim stoklama ve birim üretim (normal ve fazla mesai) maliyetleri ile birim fiyatlarının üç dönemde de değişmediği varsayılmaktadır. Diğer bir ifadeyle;

$h_{1}=h_{2}=h_{3}=h$ (Bütün ürünler bütün dönemler için eşit)

$v_{1}^{j}=v_{2}^{j}=v_{3}^{j}=v^{j}$

$y_{1}^{j}=y_{2}^{j}=y_{3}^{j}=y^{j}$

$P_{1}^{j}=P_{2}^{j}=P_{3}^{j}=P^{j}$

- Model sadece üç ürün ile sınırlandırıldığından dolayı yeniden üretim sürecindeki yıllık sabit maliyetler dikkate alınmamıştır.

\subsubsection{Hedef Programlama Modeli Hedef Kisttlart}

Dönemlik stoklama kapasiteleri şirketin hem stoklama için ayırdığ işçilik maliyetine, hem de depolama kapasitesine dikkat edilerek oluşturulmuştur. Toplam stoklama maliyeti şirketin önceki yıllarda bu departman için ayırdığı bütçe esas alınarak değerlendirilmiştir. Net kar hedefi belirlenirken, maliyeti, talep miktarlarını ve stok maliyetlerini göz önünde bulundurarak üç ürün için hedeflenen kar miktarı öngörülmüştür. Fazla mesai ile üretim maliyeti hedefi belirlenirken ise, işçilik, yemek, ulaşım, elektrik gibi fazla mesaide artış gösteren maliyetler esas alınmıştır.

- Dönemlik stoklama kapasitesini aşmama hedefleri ( $\mathrm{t}=1,2,3$ için 9 hedef)

$$
i_{t}^{j} \leq I^{j}(\mathrm{t}=1,2,3)(\mathrm{j}=\mathrm{a}, \mathrm{b}, \mathrm{c})
$$

- Toplam stoklama maliyetini minimize etme hedefi

$$
h_{t} \cdot \sum_{t=1}^{k} i_{t}^{a}+h_{t} \cdot \sum_{t=1}^{k} i_{t}^{b}+h_{t} \cdot \sum_{t=1}^{k} i_{t}^{c} \leq r \cdot p_{t}^{a} \cdot \sum_{t=1}^{k} C_{t}^{a}+r \cdot p_{t}^{b} \cdot \sum_{t=1}^{k} C_{t}^{b}+r \cdot p_{t}^{c} \cdot \sum_{t=1}^{k} C_{t}^{c}
$$

- Net karı maksimize etme hedefi

$$
\begin{aligned}
& \left(p_{t}^{a} \cdot \sum_{t=1}^{k} C_{t}^{a}+p_{t}^{b} \cdot \sum_{t=1}^{k} C_{t}^{b}+p_{t}^{c} \cdot \sum_{t=1}^{k} C_{t}^{c}\right)-\left(\left(\sum_{t=1}^{k}\left(v_{t}^{a} \cdot n_{t}^{a}+y_{t}^{a} \cdot f_{t}^{a}\right)+\right.\right. \\
& \left(\sum_{t=1}^{k}\left(v_{t}^{b} \cdot n_{t}^{b}+y_{t}^{b} \cdot f_{t}^{b}\right)+\left(\sum_{t=1}^{k}\left(v_{t}^{c} \cdot n_{t}^{c}+y_{t}^{c} \cdot f_{t}^{c}\right)\right)-\left(h_{t} \cdot \sum_{t=1}^{k} i_{t}^{a}+h_{t} \cdot \sum_{t=1}^{k} i_{t}^{b}+\right.\right. \\
& \left.h_{t} \cdot \sum_{t=1}^{k} i_{t}^{c}\right) \geq K
\end{aligned}
$$

- Dönemlik ürün talebini karşılama hedefi ( $t=1,2,3$ için 9 hedef)

$$
C_{t}^{j}=i_{t-1}^{j}+n_{t}^{j}+f_{t}^{j}-i_{t}^{j} \quad(\mathrm{t}=1,2,3)
$$

- Fazla mesai ile gerçekleştirilen üretim maliyetini minimize etme hedefi

$$
y_{t}^{a} \cdot \sum_{t=1}^{k} f_{t}^{a}+y_{t}^{b} \cdot \sum_{t=1}^{k} f_{t}^{b}+y_{t}^{c} \cdot \sum_{t=1}^{k} f_{t}^{c} \leq M
$$


Her bir ürün ve dönem için, dönemlik stoklama kapasitesini aşmama hedefi, dönemlik ürün talebini karş1lama hedefi olmak üzere 9'ar hedef oluşturulmuştur. Diğer hedefler ise bütün dönemi kapsayacak şekilde ele alınmıştır. Modele konu olan toplam 21 adet hedef vardır.

\subsubsection{Hedef Programlama Modeli Üretim Kısıtları}

Dönemlik talepleri karşılamak ve ihtiyatlılık gereği stok yapmak amaçlı normal mesai ile üretime alt sınır getirilmiş ve minimum 35 birim ile sınırlandırılmıştır. Bunu yapmaktaki bir diğer amaç ise fazla mesai ile yapılan üretimi kontrol altında tutmaktır. Aynı şekilde fazla mesai ile üretim miktarı da maksimum 30 birim ile sınırlandırılmıştır. Bunu yapmaktaki amaç ise işletmenin hedeflerinden bir tanesine konu olan fazla mesai ile üretimi azaltmaktır.

- Normal mesai ile dönemlik üretim kısıtları (9 kısıt)

$$
n_{t}^{j} \leq N_{t}^{j} \quad(\mathrm{t}=1,2,3)(\mathrm{j}=\mathrm{a}, \mathrm{b}, \mathrm{c})
$$

- Fazla mesai ile dönemlik üretim kısıtları (9 kısıt)

$$
f_{t}^{j} \leq F_{t}^{j} \quad(\mathrm{t}=1,2,3)(\mathrm{j}=\mathrm{a}, \mathrm{b}, \mathrm{c})
$$

\subsubsection{Hedef Programlama Modeli Hedef Değerleri}

Hedef değerler belirlenirken, uygulamaya konu olan şirketin bu üç ürün için ayırdığı bütçe ve diğer olanaklarından yararlanılmıştır.

- Her dönem her ürün için maksimum 50 adet stok bulundurulması $\left(I^{a}=50, I^{b}=50, I^{c}=\right.$ 50)

- Toplam stoklama maliyetinin en fazla, satışların \%1'i kadar olması $(r \leq 0,01)$

- Elde edilen net karın en az 33.000 olması $(K \geq 33.000)$

- Dönemlik ürün taleplerinin tamamen karşılanması $\left(C_{1}^{a}=60, C_{2}^{a}=34, C_{3}^{a}=8\right),\left(C_{1}^{b}=\right.$ $\left.32, C_{2}^{b}=100, C_{3}^{b}=88\right),\left(C_{1}^{c}=34, C_{2}^{c}=80, C_{3}^{c}=10\right)$

- Fazla mesai ile gerçekleştirilebilen üretim maliyetinin maksimum 1250 TL olması $\left(M^{a}+\right.$ $M^{b}+M^{c}=1250$ )

\section{Bulgular ve Yorumlar}

\subsection{AHP ile Ağırlıkların Hesaplanması}

Çalışmanın bu kısmına kadar verilen bilgiler ışığında önce AHP ile modelde kullanılan ağırlıklar hesaplanıp, daha sonra da bu ağırlıklarla oluşturulan model LINGO 11.0 yardımı ile çözülmüştür.

İşletme için yapılan uygulamada hedeflerin ağılıklarının tamamen subjektif yargılarla belirlenmesi riskine karşı, söz konusu ağırlıklar AHP kullanılarak bulunmuştur. AHP yönteminde kullanılan kriterler üretim departmanının değerlendirmeleri sonucunda oluşturulmuştur.

\section{Ağırlıklandırılan Hedefler- AHP için karar alternatifleri}

- Dönemlik stoklama kapasitesini aşmama hedefi.

- Toplam stoklama maliyetini minimize etme hedefi.

- Net karı maksimize etme hedefi.

- Dönemlik ürün talebini karşılama hedefi.

- Fazla mesai ile gerçekleştirilen üretim maliyetini minimize etme hedefi. 


\section{AHP Kriterleri}

AHP kriterleri işletmenin üretim departmanı yetkilisi tarafından belirlenmiştir.

- Yeniden üretim yapılan ürün miktarı.

- Yeniden üretim yapılan ürünlerin talebindeki dalgalanmalar.

- Yeniden üretim maliyetinin öngörülebilirliği.

- Yeniden üretilecek girdi sağlamadaki kolaylık.

- Yeniden üretimde kullanılacak yedek parçanın bulunabilirliği.

Amaç fonksiyonları ve kiterlerin yer aldığı hiyerarşik yapı Şekil 1' de gösterilmiştir.

Şekil 1. AHP kriter ve karar alternatifleri

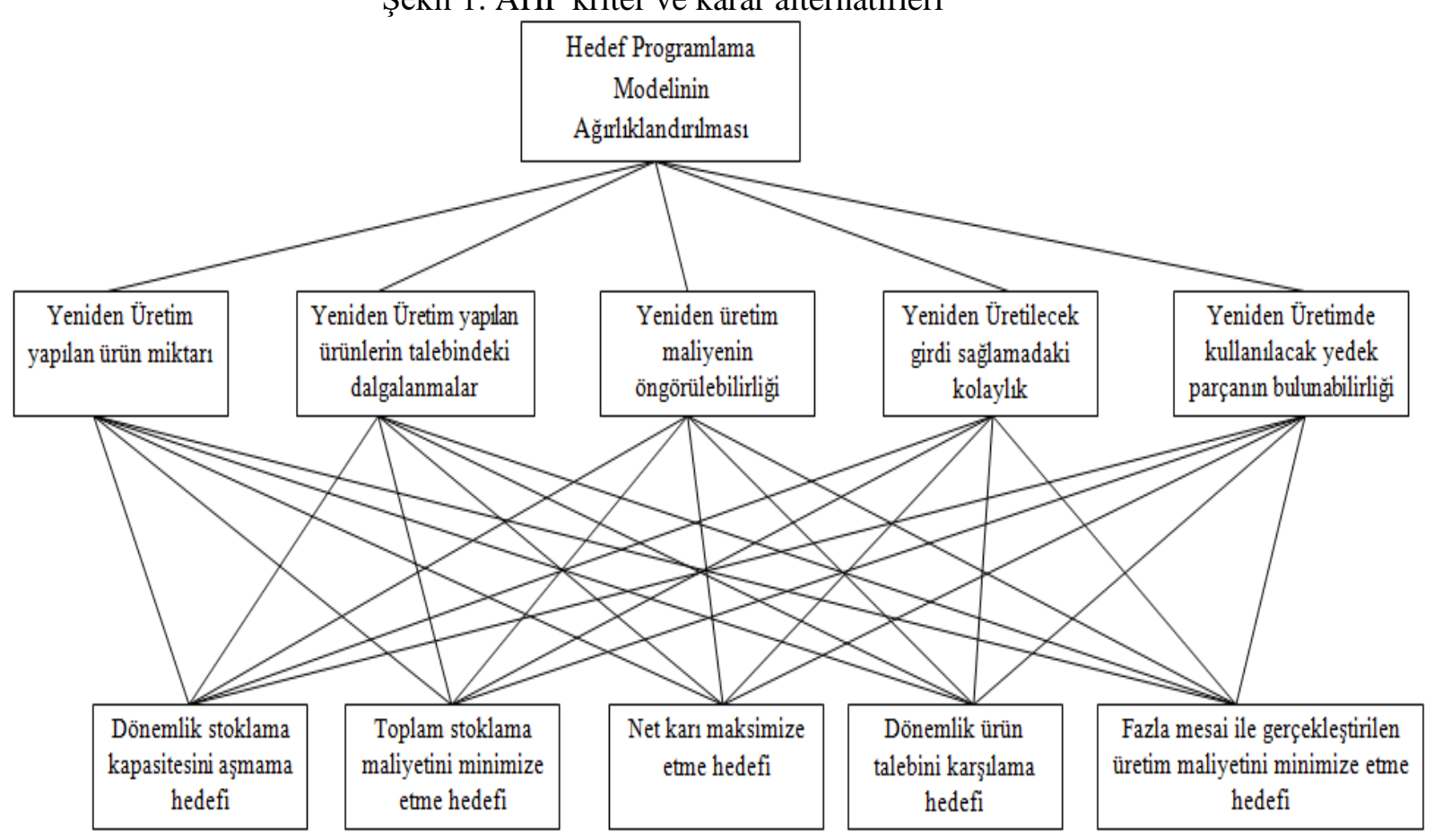

İşletme yetkililerinin fikir ve görüşleri dikkate alınıp, işletme verileri ve yapısı da gözetilerek, hedeflere verilmesi gereken ağırlıklar AHP kullanılarak belirlenmiştir. AHP' nin kriterleri şirket yetkilisinin yönlendirmeleri ile oluşturulmuş ve kriterler arası önem düzeyleri şirket yetkilisi tarafindan değerlendirilmiştir.

$$
\begin{aligned}
& \mathrm{w}_{1}=0.08 \text { (Pozitif yönlü tüm hedefler için) } \\
& \mathrm{w}_{2}=0.11 \\
& \mathrm{w}_{3}=0.29 \\
& \mathrm{w}_{4}=0.27 \text { (Pozitif ve negatif yönlü tüm hedefler için) } \\
& \mathrm{w}_{5}=0.24
\end{aligned}
$$

İşletmenin toplam 21 hedefi bulunmaktadır ve bu hedeflerden sapmaların ağırlıkları ise yapılan çözüm sonucunda yukarıdaki gibi bulunmuştur. 


\subsection{Hedef Programlama Modeli ve Çözümü}

Otomotiv yedek parça üretim işletmesinin yeniden üretim ürün portföyünde yer alan üç ürününe ilişkin stok kontrol yönetimi için oluşturulan Hedef Programlama modeli işletmeden edinilen verilere göre düzenlendiğinde aşağıdaki modele ulaşılmıştır.

Amaç Fonksiyonu;

$$
\begin{aligned}
Z_{\min }= & 0,08\left(d_{1}^{+}+d_{2}^{+}+d_{3}^{+}+d_{4}^{+}+d_{5}^{+}+d_{6}^{+}+d_{7}^{+}+d_{8}^{+}+d_{9}^{+}\right)+0,11\left(d_{10}^{+}\right)+0,29\left(d_{11}^{-}\right)+ \\
& 0,27\left(d_{12}^{-}+d_{12}^{+}+d_{13}^{-}+d_{13}^{+}+d_{14}^{-}+d_{14}^{+}+d_{15}^{-}+d_{15}^{+}+d_{16}^{-}+d_{16}^{+}+d_{17}^{-}+d_{17}^{+}+\right. \\
& \left.d_{18}^{-}+d_{18}^{+}+d_{19}^{-}+d_{19}^{+}+d_{20}^{-}+d_{20}^{+}\right)+0,24\left(d_{21}^{+}\right)
\end{aligned}
$$

$\underline{\text { Hedef kisitlar1; }}$

$$
\begin{aligned}
& i_{1}^{a}+d_{1}^{-}-d_{1}^{+}=50 \quad i_{1}^{b}+d_{4}^{-}-d_{4}^{+}=50 \quad i_{1}^{c}+d_{7}^{-}-d_{7}^{+}=50 \\
& i_{2}^{a}+d_{2}^{-}-d_{2}^{+}=50 \quad i_{2}^{b}+d_{5}^{-}-d_{5}^{+}=50 \quad i_{2}^{c}+d_{8}^{-}-d_{8}^{+}=50 \\
& i_{3}^{a}+d_{3}^{-}-d_{3}^{+}=50 \quad i_{3}^{b}+d_{6}^{-}-d_{6}^{+}=50 \quad i_{3}^{c}+d_{9}^{-}-d_{9}^{+}=50 \\
& 5 i_{1}^{a}+5 i_{2}^{a}+5 i_{3}^{a}+5 i_{1}^{b}+5 i_{2}^{b}+5 i_{3}^{b}+5 i_{1}^{c}+5 i_{2}^{c}+5 i_{3}^{c}+d_{10}^{-}-d_{10}^{+}=50 \\
& 73406-125 n_{1}^{a}-125 n_{2}^{a}-125 n_{3}^{a}-110 n_{1}^{b}-110 n_{2}^{b}-110 n_{3}^{b}-120 n_{1}^{c}-120 n_{2}^{c}- \\
& 120 n_{3}^{c}-135 f_{1}^{a}-135 f_{2}^{a}-135 f_{3}^{a}-120 f_{1}^{b}-120 f_{2}^{b}-120 f_{3}^{b}-130 f_{1}^{c}-130 f_{2}^{c}- \\
& 130 f_{3}^{c}-5 i_{1}^{a}-5 i_{2}^{a}-5 i_{3}^{a}-5 i_{1}^{b}-5 i_{2}^{b}-5 i_{3}^{b}-5 i_{1}^{c}-5 i_{2}^{c}-5 i_{3}^{c}+d_{11}^{-}-d_{11}^{+}=33000 \\
& 124+n_{1}^{a}+f_{1}^{a}-i_{1}^{a}+d_{12}^{-}-d_{12}^{+}=60 \quad i_{2}^{b}+n_{3}^{b}+f_{3}^{b}-i_{3}^{b}+d_{17}^{-}-d_{17}^{+}=88 \\
& i_{1}^{a}+n_{2}^{a}+f_{2}^{a}-i_{2}^{a}+d_{13}^{-}-d_{13}^{+}=34 \quad 64+n_{1}^{c}+f_{1}^{c}-i_{1}^{c}+d_{18}^{-}-d_{18}^{+}=34 \\
& i_{2}^{a}+n_{3}^{a}+f_{3}^{a}-i_{3}^{a}+d_{14}^{-}-d_{14}^{+}=8 \quad i_{1}^{c}+n_{2}^{c}+f_{2}^{c}-i_{2}^{c}+d_{19}^{-}-d_{19}^{+}=80 \\
& 109+n_{1}^{b}+f_{1}^{b}-i_{1}^{b}+d_{15}^{-}-d_{15}^{+}=32 \quad i_{2}^{c}+n_{3}^{c}+f_{3}^{c}-i_{3}^{c}+d_{20}^{-}-d_{20}^{+}=10 \\
& i_{1}^{b}+n_{2}^{b}+f_{2}^{b}-i_{2}^{b}+d_{16}^{-}-d_{16}^{+}=100 \\
& 135 f_{1}^{a}+135 f_{2}^{a}+135 f_{3}^{a}+120 f_{1}^{b}+120 f_{2}^{b}+120 f_{3}^{b}+130 f_{1}^{c}+130 f_{2}^{c}+130 f_{3}^{c}+d_{21}^{-}- \\
& d_{21}^{+}=1250
\end{aligned}
$$

$\begin{array}{llllll}n_{1}^{a} \geq 35 & n_{1}^{b} \geq 35 & n_{1}^{c} \geq 35 & f_{1}^{a} \leq 30 & f_{1}^{b} \leq 30 & f_{1}^{c} \leq 30 \\ n_{2}^{a} \geq 35 & n_{2}^{b} \geq 35 & n_{2}^{c} \geq 35 & f_{2}^{a} \leq 30 & f_{2}^{b} \leq 30 & f_{2}^{c} \leq 30 \\ n_{3}^{a} \geq 35 & n_{3}^{b} \geq 35 & n_{3}^{c} \geq 35 & f_{3}^{a} \leq 30 & f_{3}^{b} \leq 30 & f_{3}^{c} \leq 30\end{array}$

\section{Pozitiflik Koșulu;}

$n_{1}^{a}, n_{2}^{a}, n_{3}^{a}, n_{1}^{b}, n_{2}^{b}, n_{3}^{b}, n_{1}^{c}, n_{2}^{c}, n_{3}^{c}, f_{1}^{a}, f_{2}^{a}, f_{3}^{a}, f_{1}^{b}, f_{2}^{b}, f_{3}^{b}, f_{1}^{c}, f_{2}^{c}, f_{3}^{c}$,

$i_{1}^{a}, i_{2}^{a}, i_{3}^{a}, i_{1}^{b}, i_{2}^{b}, i_{3}^{b}, i_{1}^{c}, i_{2}^{c}, i_{3}^{c} \geq 0$

$d_{1}^{+}, d_{1}^{-}, d_{2}^{+}, d_{2}^{-}, d_{3}^{+}, d_{3}^{-}, d_{4}^{+}, d_{4}^{-}, d_{5}^{+}, d_{5}^{-}, d_{6}^{+}, d_{6}^{-}, d_{7}^{+}, d_{7}^{-}, d_{8}^{+}, d_{8}^{-}, d_{9}^{+}, d_{9}^{-}, d_{10}^{+}, d_{10}^{-}, d_{11}^{+}, d_{11}^{-}, d_{12}^{+}, d_{12}^{-}$, $d_{13}^{+}, d_{13}^{-}, d_{14}^{+}, d_{14}^{-}, d_{15}^{+}, d_{15}^{-}, d_{16}^{+}, d_{16}^{-}, d_{17}^{+}, d_{17}^{-}, d_{18}^{+}, d_{18}^{-}, d_{19}^{+}, d_{19}^{-}, d_{20}^{+}, d_{20}^{-}, d_{21}^{+}, d_{21}^{-} \geq 0$

"Direksiyon Kutusu" ürünlerinin 3 dönemlik (4'er aylık) üretim stok kontrolü hedef programlama modeli LINGO 11.0 programı ile çözülmüştür. Elde edilen değişken değerleri aşağıdaki Tablo 5'te gösterilmektedir. 
Tablo 5. LINGO çözümü sonucunda karar değişkenlerinin çözüm değerleri

\begin{tabular}{cccccc}
\hline Karar & Değişken & Karar & Değiş̧en & Karar & Değişken \\
Değişkenleri & Değerleri & Değişkenleri & Değerleri & Değişkenleri & Değerleri
\end{tabular}

\begin{tabular}{cccccc}
\hline$i_{1}^{a}$ & 0 & $n_{1}^{a}$ & 35 & $f_{1}^{a}$ & 0 \\
\hline$i_{2}^{a}$ & 0 & $n_{2}^{a}$ & 35 & $f_{2}^{a}$ & 0 \\
\hline$i_{3}^{a}$ & 27 & $n_{3}^{a}$ & 35 & $f_{3}^{a}$ & 0 \\
\hline$i_{1}^{b}$ & 65 & $n_{1}^{b}$ & 35 & $f_{1}^{b}$ & 0 \\
\hline$i_{2}^{b}$ & 0 & $n_{2}^{b}$ & 35 & $f_{2}^{b}$ & 0 \\
\hline$i_{3}^{b}$ & 0 & $n_{3}^{b}$ & 57 & $f_{3}^{b}$ & 0 \\
\hline$i_{1}^{c}$ & 45 & $n_{1}^{c}$ & 35 & $f_{1}^{c}$ & 0 \\
\hline$i_{2}^{c}$ & 0 & $n_{2}^{c}$ & 35 & $f_{2}^{c}$ & 0 \\
\hline$i_{3}^{c}$ & 10 & $n_{3}^{c}$ & 35 & $f_{3}^{c}$ & 0
\end{tabular}

İşletmenin aynı 3 dönemdeki verileriyle çözülen problemi sonucunda ulaşılan hedeflerden sapma değişkenlerinin değerleri ve negatif sapmaları ile pozitif sapmaları Tablo 6' da gösterilmektedir.

Tablo 6. LINGO çözümü hedefler ve sapma değişkenleri

\begin{tabular}{|c|c|c|c|}
\hline Hedefler & $\begin{array}{c}\text { Sapma } \\
\text { Değişkenleri }\end{array}$ & $\begin{array}{c}\text { Negatif } \\
\text { Sapmalar } \\
\left(d_{j}^{-}\right)\end{array}$ & $\begin{array}{c}\text { Pozitif } \\
\text { Sapmalar } \\
\left(d_{j}^{-}\right)\end{array}$ \\
\hline \multirow{9}{*}{ Dönemlik stoklama kapasitesini aşmama hedefleri } & $d_{1}$ & 50 & 0 \\
\hline & $d_{2}$ & 50 & 0 \\
\hline & $d_{3}$ & 23 & 0 \\
\hline & $d_{4}$ & 0 & 15 \\
\hline & $d_{5}$ & 50 & 0 \\
\hline & $d_{6}$ & 50 & 0 \\
\hline & $d_{7}$ & 5 & 0 \\
\hline & $d_{8}$ & 50 & 0 \\
\hline & $d_{9}$ & 40 & 0 \\
\hline Toplam stoklama maliyetini minimize etme hedefi & $d_{10}$ & 0 & 0 \\
\hline Net karı maksimize etme hedefi & $d_{11}$ & 0 & 0 \\
\hline \multirow{9}{*}{ Dönemlik ürün talebini karşıllama hedefi } & $d_{12}$ & 0 & 99 \\
\hline & $d_{13}$ & 0 & 1 \\
\hline & $d_{14}$ & 0 & 0 \\
\hline & $d_{15}$ & 0 & 47 \\
\hline & $d_{16}$ & 0 & 0 \\
\hline & $d_{17}$ & 31 & 0 \\
\hline & $d_{18}$ & 0 & 20 \\
\hline & $d_{19}$ & 0 & 0 \\
\hline & $d_{20}$ & 0 & 15 \\
\hline $\begin{array}{l}\text { Fazla mesai ile gerçekleştirilen üretim maliyetini minimize } \\
\text { etme hedefi }\end{array}$ & $d_{21}$ & 1250 & 0 \\
\hline
\end{tabular}

Dönemlik stok kapasitesini aşmama hedefleri olan $\mathrm{d}_{1}$ ile $\mathrm{d}_{9}$ arasındaki hedeflerin pozitif sapmalarının minimum olması istenmiş ve b ürününün 1. dönemdeki stok kapasitesi hedefi hariç, diğer hedefler başarılmıştır. Toplam stoklama maliyetini minimize etme, net karı maksimize etme ve fazla mesai ile gerçekleştirilen üretim maliyetini minimize etme hedefleri $\left(d_{10}, d_{11}, d_{21}\right)$ hiç bir istenmeyen sapma olmadan başarılmıştır. Dönemlik ürün talebini karşılama hedeflerinin $\left(\mathrm{d}_{12}\right.$ ile 
$\mathrm{d}_{20}$ arası) hiç bir pozitif veya negatif sapma olmadan gerçekleşmesini isteyen işletme a ürününün 3. dönemi, b ürününün 2. dönemi, c ürününün 2. dönemi haricinde hedeflerine ulaşamamış ve istenmeyen sapmalar meydana gelmiştir.

\section{Sonuç ve Öneriler}

20. yüzyılın ikinci yarısından itibaren en üst düzeye ulaşan makineleşme, teknolojinin sınırları aşması ve globalleşmenin etkisiyle uluslararası ticaretin derinleşmesi rekabetin yoğun olarak yaşandığı bir piyasa ortamını beraberinde getirmiştir. Rekabetin bu kadar yoğun olarak yaşandığı piyasa ortamlarında hızlı ve verimli karar alabilen işletmeler bir adım öne çıkmaktadır.

Aynı anda birçok fonksiyonu yerine getiren işletmeler, karar alırken de aynı şekilde birden fazla kısıtı ve birden fazla amacı göz önünde bulundurmak zorunda kalmaktadır. İşletmelerin alması gereken kararlar, doğası gereği belirsiz ortamlarda alındığından ve bu belirsizlik ortamı işletmenin geleceğini etkileyeceğinden, kararın isabeti işletmenin başarısını doğrudan ilgilendirmektedir. İşte bu belirsizlik içinde, birden çok amaç göz önünde bulundurularak karar alınması gerektiğinde ÇAKV Metotları ile karşılaşılmaktadır.

$\mathrm{Bu}$ çalışmada ÇAKV metotlarından Hedef programlama ve ÇNKV metotlarından AHP kullanılarak bir üretim işletmesinin stok kontrol politikasındaki hedefler doyuma ulaştırılmıştır.

Yeniden üretim faaliyeti gerçekleştiren otomotiv şirketinin yeniden üretim ürün portföyünden 3 ürünün 3 dönemlik stok kontrol politikasını belirleyen 5 ana hedef (toplam 21 hedef) Hedef Programlama modeli ile doyuma ulaştırılmıştır. Ağırlıklı (Weighted) Hedef Programlama kullanılarak oluşturulan modelin ağırlıkları, ÇNKV metotlarından AHP kullanılarak belirlenmiştir. AHP'nin karar problemi, modelin amaç fonksiyonu katsayılarının ağırlıklandırılması olarak belirlenmiştir. Karar alternatifleri modele konu olan ana hedeflerdir. Kriterler ise işletme yetkilisinin yeniden üretim faaliyetine ilişkin olarak belirlediği kısıtlamalardır. Karar alternatifleri, her bir kritere göre karşılaştırma matrislerine yerleştirilmiş ve Excel for Windows yardımıyla çözüme ulaşılmıştır. Her bir çözümün tutarlılık oranının 0.1 'den küçük olduğundan, yani çözümün tutarlı olduğundan emin olunduktan sonra bulunan ağırlıklar modelin amaç fonksiyonuna eklenerek LINGO 11.0 paket programı ile çözüm gerçekleştirilmiştir. Çözüm sonucunda bulunan değerler Tablo 5 ve 6' da gösterilmektedir.

Elde edilen sonuçlara göre işletme dönemlik stoklama kapasitesini aşmama hedefini B ürünü haricinde gerçekleştirmiştir. A ürünü için stoklama kapasitesi 1. ve 2. dönemde tamamen kullanılmış 3. dönem ise 23 birim stoklanmış yani 27 birim hedeften negatif sapma gerçekleşmiştir. B ürünü için 1. dönemde hedeften 15 birim pozitif sapma olmuştur. 2. ve 3 . dönem ise herhangi bir sapma meydana gelmeden bütün stoklama kapasitesi kullanılmıştır. C ürünü için ise 1. dönem ve 3. dönemde sirasıyla 5 birim ve 40 birim kullanılmayan stok kapasitesi kalmıştır. Yani işletme 1. dönemde 45 birim, 3. dönemde ise 10 birim stoklamıştır. B ürünü için 2. dönemde herhangi bir sapma olmadan bütün stoklama kapasitesi kullanılmıştır.

Toplam stoklama maliyetini minimize etme ve net karı maksimize etme hedeflerini başaran işletme, herhangi bir sapma meydana gelmeden 3 dönemi tamamlamıştır. Maksimum 735 TL olan stoklama maliyetinin tamamını kullanan işletme bu miktarın üzerine çıkmadan stoklama maliyetini gerçekleştirmiştir. Aynı şekilde 3 ürünün 3 dönemlik satışlarından minimum 33000 TL kar hedefleyen işletme söz konusu karı gerçekleştirmiştir.

İhtiyatlı olmak ve fazla mesai ile üretimi kısıtlamak adına her ay minimum 35 birim normal mesai ile üretim yapan işletme $\mathrm{A}$ ve $\mathrm{C}$ ürünlerini 3 dönemde 35 birim üretmiştir. $\mathrm{B}$ ürününde ise 1 . ve 2 . dönemler 35 birim üretim yapılmış 3 . dönem ise 57 birim üretilmiştir.

Dönemlik ürün talebini tamamen karşılamayı hedefleyen işletme, pozitif ve negatif bir sapma meydana gelmesini istememektedir. Bu hedefini tam anlamıyla gerçekleştiremeyen işletme A ürününün 1. ve 2. dönemdeki talebinin sırasıyla 99 ve 1 birim üzerine çıkmış, 3. dönemde talep tamamen karşılanmıştır. B ürününde 1. dönem 47 birim talebin üzerine çıkan 
işletme, 3. dönem 31 birim talebi karşlayamamıştır. B ürünü için 2. dönemde bütün talep tamamen karşılanmıştır. C ürününde ise 1 . ve 3 . dönem sırasıyla 20 ve 15 birim istenilen talebin üzerine çıkılmış, 2. dönem ise talep herhangi bir sapma meydana gelmeden karşılanmıştır.

Normal mesai ile ayda minimum 35 tane üretim yapmak zorunda olan işletme ihtiyatlılık adına gerçekleştirdiği bu durum sayesinde 3 dönem boyunca hiç bir üründen fazla mesai ile üretim yapmak zorunda kalmamıştır. Maksimum 1250 TL ayırdığı fazla mesai ile üretim maliyetini hiç kullanmamıştır.

Görüldüğü gibi birçok hedefini başarıyla doyuma ulaştıran işletme kısmen başarılı bir seyir izlemektedir. Bir dönemde stok kapasitesini aşan işletme bunun önüne geçebilmek için ya üretimi ve satışı az olan bir ürünün stok kapasitesinden yararlanmalı, ya da o ürün için tekrar üretim-satış planlaması yapıp fazla stoku engellemelidir. Aynı şekilde talebin eksik veya fazla çıkması konusunda da önlem alması gereken işletme fazla arzını değerlendirmek için yeni pazarlar aramalı, eksik talep için ise üretim programını gözden geçirerek gerekli önlemleri almalidır.

Sonuç olarak hedef programlama ile modellenen stok kontrol problemi hedeflerini başarılı bir şekilde gerçekleştirmiştir. Fakat her ÇKKV yöntemi gibi Hedef Programlamada da sonuçlar tahminidir. Yani tahminler geleceğe ilişkin yapıldığında mükemmellikten uzaktır. İşletme yapılan bu çalışmayı dikkate alırken aynı zamanda işletmenin olanaklarını da dikkate alarak kararlarını vermelidir. Çünkü veriler derlendiğinde işletme yeniden üretim faaliyetini yalnızca bir yıldan beri yaptığından, model oluşturulurken çok fazla sayısal veri kullanılmamış, işletme mühendislerinin subjektif yargılarından yararlanılmıştır.

Yapılan çalışma hedef programlama ile modellenen stok kontrol politikasının hedeflerini başarılı bir şekilde doyuma ulaştırdığını gözler önüne sermektedir. Bundan sonraki çalışmalarda subjektif yargılardan uzak nicel verilerle işlem gerçekleştirilirse, bunun işletmenin uzun vadede hem karına hem de üretim sistemine pozitif katkı sağlayacağı düşünülmektedir.

\section{Kaynakça}

Anderson, D. R., Sweeney, D. J. ve Williams, T. A. (2001). Quantitative Methods for Business (8th edition), Ohio: South-Western College Publishing.

Aouni, B. ve Kettani, O. (2001). Goal Programming Model: A Glorious History and A Promising Future, European Journal of Operational Research, 133(2001): 225-231.

Bhushan, N. ve Rai, K. (2004). Strategic Decision Making Applying the Analytic Hierarchy Process, New York: Springer-Verlag London Limited.

Charnes, A. ve Cooper, W.W. (1961). Management Models and Industrial Applications of Linear Programming, New York: John Wiley \& Sons, Inc.

Charnes, A. ve Cooper, W.W. (1977). Goal Programming and Multiple Objective Optimizations, European Journal of Operational Research, 1(1977): 39-54.

Chase, R. B., Aquilano, N. J. ve Jacobs, F. R., (1998). Production and Operations Management: Manufacturing and Services, Indiana: Irvin/McGraw-Hill.

Chung, C.J. ve Wee, H.M. (2011). Short Life-Cycle Deteriorating Product Remanufacturing in a Green Supply Chain İnventory Control System, International Journal of Production Economics, 129(1): 195-203.

Demir, H. ve Gümüşoğlu, Ş. (2009). Üretim Yönetimi (İşlemler Yönetimi), İstanbul: Beta Basım Yayım Dağıtım A.Ş. 
Dowlatshahi, S. (2005). A Strategic Framework For The Design and Implementation of Remanufacturing Operations in Reverse Logistics, International Journal of Production Research, 43(16): 3455-3480.

Giove, S., Brancia, A., Satterstrom, F. K. ve Linkov, I. (2009). Decision Support Systems and Environment: Role of MCDA, İçinde: Decision Support Systems for Risk-Based Management of Contaminated Sites (Ed. Antonio Marcomini, Glenn W. Suter ve Andrea Critto), NewYork: Springer Science \& Business Media.

Gungor, A. ve Gupta, S.M. (1999). Issues in Environmentally Conscious Manufacturing and Product Recovery: A Survey, Computers and Industrial Engineering, 36(1999): 811-853.

Gürler, İ. (2010). Yeniden Üretim Sürecinde Tasarım, Planlama, Lojistik Faaliyetlerinin İncelenmesi ve Türkiye Açısından Değerlendirilmesi, Dokuz Eylül Üniversitesi Sosyal Bilimler Enstitüsü, Doktora Tezi, İzmir.

Ignizio, J. P. (1978). A Review of Goal Programming: A Tool for Multiobjective Analysis, The Journal of The Operational Research Society, 29(11): 1109-1119.

Ignizio, J. P. (1983). A Note on Computational Methods in Lexicographic Linear Goal Programming, Operational Research Society, 34(6): 539-542.

Ignizio, J. P. (1989). On The Merits and Demerits of Integer Goal Programming, Operational Research Society, 40(8): 781-785.

Inderfurth, K. ve Van der Laan, E. (2001). Leadtime Effects and Policy İmprovement for Stochastic Inventory Control with Remanufacturing, International Journal of Production Economics, 71(1-3): 381-390.

Kaçtıoğlu, S. ve Şengül, Ü. (2010). Erzurum Kenti Ambalaj atıklarının Geri Dönüşümü İçin Tersine Lojistik Ağı Tasarımı ve Bir Karma Tamsayılı Programlama Modeli, Atatürk Üniversitesi İktisadi ve İdari Bilimler Dergisi, 24(1): 89-112.

Kongar, E. ve Gupta, S. M. (2000). A Goal Programming Approach to the Remanufacturing Supply Chain Model, Environmentally Conscious Manufacturing, 4193(1): 167-178.

Kumar, S. ve Malegeant, P. (2006). Strategic Alliance in A Closed-Loop Supply Chain, A Case Of Manufacturer and Eco-Non-Profit Organization, Technovation, 26(2006): 1127-1135.

Lee, S. M. (1972). Goal Programming for Decision Analysis. Philedelphia: Auerbach Publishers

Mahadevan, B., Pyke, D.F. ve Fleischemann, M. (2003). Periodic Review, Push Inventory Policies for Remanufacturing, European Journal of Operational Research, 151(3): 536-551.

Nenes, G., Panagiotidou, S. ve Dekker, R. (2010). Inventory Control Policies for Inspection and Remanufacturing of Returns: A Case Study, International Journal of Production Economics, 125(2): 300-312.

Özdemir, A. (2005). Kobi'lerin Stok Kontrol Yönetiminde Hedef Programlama Modelının Uygulanmas1, 2. KOBI'ler ve Verimlilik Kongre Kitabı (ss.561-568), Düzenleyen: İstanbul Kültür Üniversitesi, Milli Prodüktivite Merkezi ve KOSGEB, İstanbul, 02-03 Aralık 2005.

Saaty, T. L. ve Sodenkamp, M. (2010). The Analytic Hierarchy and Analytic Network Measurement Processes: The Measurement of Intangibles Decision Making under Benefits, Opportunities, Costs and Risks, İçinde: Handbook of Multicriteria Analysis (Ed. Constantin Zopounidis ve Panos M. Pardalos), Heidelberg: Springer-Verlag Berlin.

Takahashi, K., Morikava, K., Takeda, M. D. ve Mizuno, A. (2007). Inventory Control for A Markovian Remanufacturing System With Stochastic Decomposition Process, International Journal of Production Economics, 108(1-2): 416-425. 
Thierry, M., Salomon, M., Van Nunen, J. ve Van Wassenhove, L. (1995). Strategic Issues in Product Recovery Management, California Management Review, 37(2): 114-135.

Van der Laan, E. ve Salomon, M. (1997). Production Planning and Inventory Control with Remanufacturing and Disposal, European Journal of Operational Research, 102(2): 264-278.

Van der Laan, E., Dekker, R. ve Salomon, M. (1996). Product Remanufacturing and Disposal: A Numerical Comparison of Alternative Control Strategies, International Journal of Production Economics, 45(1996): 489-498.

Van der Laan, E., Salomon, M., Dekker, R. ve Wassenhove, L.V. (1999). Inventory Control in Hybrid Systems with Remanufacturing, Management Science, 45(5): 733-747.

Wise, K. ve Perushek, D.E. (2000). Goal Programming as a Solution Technique for the Acquisitions Allocation Problem, Library and Information Science Research, 22(2): 165-183.

Zahedi, F. (1986). The Analytic Hierarchy Process: A Survey of the Method and Its Applications, Institue for Operations Research and The Management Science, 16(4): 96-108.

Zhou, L., Naim, M.M., Tang, O. ve Towill, D.R. (2006). Dynamic Performance of A Hybrid Inventory System with A Kanban Policy in Remanufacturing Process, Omega, 34(6): 585-598. 